\title{
Patients with Schizophrenia and Self-Care
}

\author{
Slavica Arsova*, Stojan Bajraktarov, Ivan Barbov, Kadri Hadzihamza \\ University Psychiatry Clinic, Skopje, Republic of Macedonia
}

\begin{abstract}
Citation: Arsova S, Bajraktarov S, Barbov I, Hadzihamza K. Patients with Schizophrenia and Self-Care. OA Maced J Med Sci. 2014 Jun 15; 2(2):289-292.

http://dx.doi.org/10.3889/oamjms.2014.048

Key words: schizophrenia; treatment; self-care; psychosocial activity; Republic of Macedonia.

"Correspondence: Slavica Arsova, MD, PhD. University Psychiatry Clinic, ul. Belgradska bb. Skopje 1000, Republic of Macedonia. Phone: 0038970255436. E-mail: arsova_s@yahoo.com Received: 01-Apr-2014; Revised: 15-May2014; Accepted: 17-May-2014; Online first: 12-Jun-2014

Copyright: () 2014 Arsova et al. This is an open access article distributed under the terms of the Creative Commons Attribution License, which permits unrestricted use, distribution, and reproduction in any medium, provided the original author and source are credited.

Competing Interests: The authors have declared that no competing interests exist.
\end{abstract}

\begin{abstract}
INTRODUCTION: Patients with schizophrenia have severe problems with self-care which affects their quality of life.

OBJECTIVE: The aim of the paper was to monitor self-care in patients with schizophrenia and to find out the differences regarding socio-demographic characteristics and ambulatory and day hospital treatment.

METHOD: The investigation included 120 subjects each with diagnosis F20 according to ICD 10 criteria; divided in two groups of 60 patients regarding their actual treatment (the first group received ambulatory care whereas those from the second group had a day hospital treatment). Patients were of different age and gender, receiving regular antipsychotic therapy. They were included in individual and group psychosocial therapeutic procedures during the day hospital treatment. The investigation utilized the following diagnostic instruments: standardized clinical interview and Personal and social performance scale (PSP scale), non-standardized questionnaire of socio-demographic data, family support and existence of mental disorder in other family members.
\end{abstract}

RESULTS: The results have shown better personal and social functioning in patients who had family support, in those who are employed, in those with no mental disorder in other family members and in patients on day hospital treatment against patients receiving ambulatory care.

CONCLUSION: Day hospital treatment, family support and social support improve self-care of patients with schizophrenia.

\section{Introduction}

Over the last two decades psychosocial activities have been directed towards to improve the personal and social functioning of patients with schizophrenia which means not only treatment of the schizophrenic simptomatology.

Schizophrenia is a chronic mental disorder that affects emotions, cognition behaviour. The consequences are poor psychosocial functioning and a low quality of life in those people.

Quality of life means the ability to play socially defined roles such as: homemaker, worker, student, spouse and, friend, and additionally, this give the individual a feeling of satisfaction and the ability to take care of him/her and to enjoy the life [1].

Psychosocial interventions inducted on a day hospital treatment would enable better therapeutic collaboration, effective pharmacological treatment, better control of patient disorder and their life in general and taking self care of themselves with greater personal satisfaction [2-4].

The aim of this study was to monitor self-care in patients with schizophrenia and to find out the differences regarding socio-demographic characteristics and ambulatory and day hospital treatment.

\section{Materials and Method}

The investigation included 120 subjects each with diagnosis F20 according to ICD 10 criteria.; Subjects were divided in two groups of 60 patients regarding their actual treatment. The first group received ambulatory care whereas those from the second group had a day hospital treatment). Patients were of different age and gender and were, receiving regular antipsychotic therapy. They were included in individual and group psychosocial therapeutic procedures during the day hospital treatment. The subjects of both groups were evaluated at the beginning of treatment and after 6 months, after ambulatory or day hospital treatment.

The investigation utilized the following diagnostic instruments: standardized clinical interview; personal and social performance scale (PSP scale) 
[5]; non-standardized questionnaire of sociodemographic data including, family support and existence of mental disorder in other family members.

\section{Results}

Distribution in Table 1 shows absence of problems in self-care in 4 (3.3\%) unemployed, 2 $(2.7 \%)$ employed subjects and in $2(1.7 \%)$ retired persons. Manifested problems were found in 14 (11.7\%) unemployed, 9 (7.5\%) employed subjects, 1 student and 3 retired subjects, whereas marked problems were found in $24(20 \%)$ employed subjects, $6(5 \%)$ unemployed, and 4 (3.3\%) retired subjects. Very severe problems in self-care were experienced by $7(5.8 \%)$ unemployed subjects and by only 1 $(0.8 \%)$ retired person.

Table 1: Self-care - employment status of the subjects.

\begin{tabular}{|c|c|c|c|c|c|}
\hline \multirow[t]{2}{*}{ Self-care } & \multicolumn{4}{|c|}{ Employment } & \multirow[t]{2}{*}{ Total } \\
\hline & Unemployed & Employed & Student & Retired persons & \\
\hline 1 absent & 4 (3.33\%) & $2(1.67 \%)$ & 0 & $2(1.67 \%)$ & $8(6.67 \%)$ \\
\hline 2 mild & $9(7.50 \%)$ & $4(3.33 \%)$ & 0 & $1(0.83 \%)$ & $14(11.67 \%)$ \\
\hline 3 manifested & $14(11.67 \%)$ & $9(7.50 \%)$ & $1(0.83 \%)$ & $3(2.50 \%)$ & $27(22.50 \%)$ \\
\hline 4 marked & $24(20.0 \%)$ & $6 \quad(5.0 \%)$ & 0 & $4(3.33 \%)$ & 34 (28.33\%) \\
\hline 5 severe & $23(19.17 \%)$ & $3(2.50 \%)$ & $1(0.83 \%)$ & $2(1.67 \%)$ & $29(24.17 \%)$ \\
\hline 6 very severe & $7(5.83 \%)$ & 0 & 0 & $1(0.83 \%)$ & $8(6.67 \%)$ \\
\hline Total & $81(67.50 \%)$ & $24(20.0 \%)$ & $2(1.67 \%)$ & 13 (10.83\%) & $120(100 \%)$ \\
\hline
\end{tabular}

Kruskal-Wallis $\mathrm{H}=7.13, \mathrm{p}=0.028$

Subjects with different employment status $(\mathrm{p}<$ 0.05 ) showed differences in the modalities of the Selfcare Scale, (students were not included in the statistical analysis). Unemployed subjects significantly more often had marked or severe problems in taking care of themselves, while employed subjects significantly less often had very severe problems.

Distribution of the modalities on the Self-care Scale in subjects with positive and negative family history of psychic disorder is illustrated in Table 2. No problems in self-care from families with and without history of psychic disorder, were registered in 3 $(2.5 \%)$ and $5(4.2 \%)$ subjects, respectively. From Table 2, the group of subjects with positive history of family psychic disorder, with severe problems of selfcare predominated was $18(15 \%)$, and in the group of subjects with negative history of family psychic disorder, $23(19.2 \%)$ subjects had severe problems. Two subjects $(1.7 \%)$ from family without history of psychic disorder and $6(5 \%)$ from family with history of psychic disorder experienced very severe problems of self-care.

Tested difference of the modalities on the Self-care Scale in subjects with positive and negative history of family psychic disorder was statistically significant for the level of significance of $p<0.05$. Severe and very severe problems category of subjects in taking care of themselves, were more often found in those who had family member(s) with mental disorder.

\begin{tabular}{|c|c|c|c|}
\hline \multirow[t]{2}{*}{ Self-care } & \multicolumn{2}{|c|}{$\begin{array}{c}\text { Presence of history of family psychic } \\
\text { disorder }\end{array}$} & \multirow[t]{2}{*}{ Total } \\
\hline & No & Yes & \\
\hline 1 absent & $5(4.17 \%)$ & $3(2.50 \%)$ & $8(6.67 \%)$ \\
\hline 2 mild & $11(9.17 \%)$ & $3(2.50 \%)$ & $14(11.67 \%)$ \\
\hline 3 manifested & 17 (14.17\%) & $10(8.33 \%)$ & $27(22.50 \%)$ \\
\hline 4 marked & $23(19.17 \%)$ & 11 (9.17\%) & 34 (28.33\%) \\
\hline 5 severe & $11(9.17 \%)$ & 18 (15.0\%) & $29(24.17 \%)$ \\
\hline 6 very severe & $2(1.67 \%)$ & $6(5.0 \%)$ & $8(6.67 \%)$ \\
\hline Total & 69 (57.50\%) & $51(42.50 \%)$ & $120(100 \%)$ \\
\hline
\end{tabular}

Among subjects who had no problems in taking care, the largest numbers were those who had family support $-5(4.17 \%)$ and were also predominant in the group of subjects with mild problems -7 $(5.83 \%)$. Twenty subjects $(16.7 \%)$ with marked difficulties in self-care received a small support from their families. However $14(11.7 \%)$ of these subjects thought that their families strongly supported them. Among subjects who had very severe problems in self-care, the largest number and percentage belonged to those who thought their family was not supportive $-6(5 \%)$.

Tested difference in the distribution of the modalities on the Self-care Scale related to the perception of the subjects for the support they received from their families was highly statistically significant $(p<0.01)$. In subjects who did not perceive their family as supportive there were more common severe problems in self-care; in subjects who received small family support there were significantly more severe problems in self-care, compared to subjects who had significant family support and more often had no problems in self-care (Table 3 ).

Table 3: Self care - family support.

\begin{tabular}{|c|c|c|c|c|}
\hline \multirow{2}{*}{ Self-care } & \multicolumn{3}{|c|}{ I think the family is supportive } & \multirow{2}{*}{ Total } \\
\hline & No & Little & Very much & \\
\hline 1 absent & $1(0.83 \%)$ & $2(1.67 \%)$ & $5(4.17 \%)$ & $8(6.67 \%)$ \\
\hline 2 mild & $3(2.50 \%)$ & $4(3.33 \%)$ & $7(5.83 \%)$ & $14(11.67 \%)$ \\
\hline 3 manifested & $4(3.33 \%)$ & $8(6.67 \%)$ & $15(12.50 \%)$ & $27(22.50 \%)$ \\
\hline 4 marked & 0 & $20(16.67 \%)$ & $14(11.67 \%)$ & $34(28.33 \%)$ \\
\hline 5 severe & $3(2.50 \%)$ & $21(17.50 \%)$ & $5(4.17 \%)$ & $29(24.17 \%)$ \\
\hline 6 very severe & $6(5.0 \%)$ & $1(0.83 \%)$ & $1(0.83 \%)$ & $8(6.67 \%)$ \\
\hline Total & $17(14.17 \%)$ & $56(46.67 \%)$ & $47(39.17 \%)$ & $120(100 \%)$ \\
\hline
\end{tabular}

Six (6) months after the grouping of subjects, in the day hospital treatment group had - mild difficulties of self care [34 (56.7\%)], with manifestation of problems in $16(26.7 \%)$. In ambulatory treated patients 20 (33.3\%) demonstrated manifest problems; $17(28.3 \%)$ had marked problems and-14 (23.3\%), sever difficulties in taking care of themselves. There was a high statistically significant difference between subjects who were treated daily in a hospital and the those who were ambulatory- cared., Patients who were treated on a daily basis in hospital did not have any hard times regarding their daily self care, $(p<0.0001)$.

Table 4: Self care-DC/Ambulatory Care.

\begin{tabular}{|c|c|c|c|c|}
\hline \multirow{2}{*}{ Self-care/ $6 \mathrm{M}$} & \multicolumn{2}{|c|}{$\overline{D C}$} & \multicolumn{2}{|c|}{ Amb.Care } \\
\hline & $\mathrm{N}$ & $\%$ & $\mathrm{~N}$ & $\%$ \\
\hline 1 absent & 6 & 10.0 & 2 & 3.33 \\
\hline 2 mild & 34 & 56.67 & 5 & 8.33 \\
\hline 3 manifest & 16 & 26.67 & 20 & 33.33 \\
\hline 4 marked & 3 & 5.0 & 17 & 28.33 \\
\hline 5 severe & 1 & 1.67 & 14 & 23.33 \\
\hline 6 very severe & 0 & 0 & 2 & 3.33 \\
\hline Total & 60 & 100 & 60 & 100 \\
\hline
\end{tabular}




\section{Discussion}

The results obtained in this study demonstrated unsatisfactory psychosocial functioning in both groups of patients. Thus, poor quality of life of patients with schizophrenic disorder was observed. Most of the unemployed patients, about 30\% lost their jobs after because of the psychosocial invalidation and stigmatization of the society.

Our results and those reported in literature present a depressive symptomatology in these patients [6-8]. However, the six -month continuous treatment brought improvement in functioning, which was statistically significant in those receiving day hospital treatment. Our results are in therefore in agreement with those presented by other authors, who suggested that integrated psychopharmacological and psychosocial treatment was indispensable for the inclusion of these patients again in the social functioning of, taking care for themselves as well as their families, and, establishing social contacts, employment, etc. as part of, inclusion in societal life $[1,2,4,9]$.

NICE rec. for the treatment and recovery of the patients with schizophrenia are community based treatment witch means individual treatment tailored for each patient, treatment in the community, ambulatory care, service level interventions, acute day hospital treatment and in the day hospital centers. NICE rec. are CBT treatment, family interventions and art therapy in the recovery period and after for faster and better reintegration and resocialisation [21].

Data presented in literature point out to poor psychosocial functioning of patients with schizophrenic disorders and poor quality of life in general [9]. Koivumaa-Honkanen et al. in their investigation used different scales for assessment of quality of life (QOL) in patients with schizophrenia and found out poorer functioning in these patients compared to the remaining psychiatric patients [10]. Sullivan et al. conducted a study among a population of schizophrenic patients divided in three groups (patients in psychiatric institutions, patients who live alone and those who live in centers for psychosocial support) and compared them with the healthy population. Using the interview for assessment of QOL, they obtained results that revealed poorer quality of life in all three groups of schizophrenic subjects against the healthy ones. The biggest differences were observed in satisfaction from social life, finances and employment.

Malm et al. using the semi-structured questionnaire (QOLC) for assessment of quality of life of 40 schizophrenic subjects 2 years after their last hospitalization, found out dissatisfaction in almost all aspects of living and especially in social relations, education, finances, etc. [11].

Majority of studies identify the relationship and diversity of quality of life in schizophrenic patients and some sociodemographic characteristics [12]. Shtasel et al. in their study of schizophrenic patients detected better functioning of female subjects than male $[13,14]$.

On the other hand, Lehman in his study revealed that individuals who were married had better quality of life that those who were not married $[15,16]$. With regard to education many studies have revealed poorer quality of life in those schizophrenic patients who had a higher levels of education [17].

Other researchers have presented the correlation between the presence of neuroleptic symptomatology, negative schizophrenic symptomatology and distinct depression with low quality of life satisfaction [17, 18].

Relationship between the treatment of these patients and their quality of life is underlined in many studies the results obtained confirmed better psychosocial functioning with usage of the secondgeneration antipsychotics and, better quality of life in those subjects who had integrated psychopharmacological and psychosocial treatment (family interventions, supportive interventions, cognitive behavioral, training for social skills, and especially in day hospital settings or other similar psychosocial facilities) $[1,3,19,20]$.

In conclusion, daily hospital psychosocial therapeutic treatment in combination with regular antipsychotic therapy, family and social support helps in more rapid reintegration and re-socialization and better quality of life in patients with schizophrenia.

\section{References}

1. Essock S, Kontos N. Implementing assertive community treatment teams. Psychiatr Serv. 2005; 46:679-683,

2. Aberg-Wistedt A, Cressell T, Lidberg Y, Liljenberg B, Osby U. Two-year outcome of team-based intensive case management for patients with schizophrenia. PsychiatrServ. 1995; 46:1263 6.

3. Arango C, Bombín I, González-Salvador T, García-Cabeza I, Bobes J. Randomised clinical trial comparing oral versus depot formulations of zuclopenthixol in patients with schizophrenia and previous violence. Eur Psychiatry. 2006; 21:34-40.

4. Bachrach LL. Psychosocial rehabilitation and psychiatry in the care of long-term patients. American Journal of Psychiatry. 2002; 149:1455-1463.

5. Morosini PL, Magliano L, Brambilla L, Ugolini S, Pioli R. Development, reliability and acceptability of a new version of the DSM-IV Social and Occupational Functioning Assessment Scale (SOFAS) to assess routine social functioning. Acta Psychiatr Scand. 2000;101(4):323.

6. Schwartz RC. Self-awareness in schizophrenia: its relationship to depressive symptomatology and broad psychiatric impairments. J Nerv Ment Dis. 2001; 189: 401-403.

7. Sim K, Mahendran R, Siris SG, Heckers S, Chong SA Subjective quality of life in first episode schizophrenia spectrum disorders with comorbid depression. Psychiatry Res. 2004; 129:141-147. 
8. Slaughter J, Lehman A, Myers P. Quality of life of severely mentally ill adults in residential care facilities. Adult Residential Care Journal. 2001; 5:97-111.

9. Lieberman JA, Drake RE, Sederer LI, Belger A, Keefe R, Perkins D, Stroup S. Science and recovery in schizophrenia. Psychiatr Serv. 2008;59(5):487.

10. Koivumaa-Honkanen $H T$, Viinamäki $H$, Honkanen $R$, Tanskanen A, Antikainen R, Niskanen L, Jääskel äinen J, Lehtonen J. Correlates of life satisfaction among psychiatric patients. Acta Psychiatr Scand. 1996;94(5):372-8.

11. Malm U, May $P$, Dencker S: Evaluation of the quality of life in schizophrenic outpatients: A checklist. Schizophr Bull. 2001; 7: 477-486.

12. Borge L, Martinsen EW, Ruud T, Watne O, Friis S. Quality of life, loneliness, and social contact among long-term psychiatric patients. Psychiatr Serv. 1999;50(1):81-4.

13. Slaughter J, Lehman A, Myers P. Quality of life of severely mentally ill adults in residential care facilities. Adult Residential Care Journal. 2001; 5:97-111.

14. Skantze K, Malm U, Dencker S, et al. Comparison of quality of life with standard of living in schizophrenic outpatients. $\mathrm{Br} \mathrm{J}$ Psychiatry. 2002; 161: 797-801.

15. Lehman A. Measures of quality of life among persons with severe and persistent mental disorders. Soc Psychiatry Psychiatr Epidemiol. 2006; 31:78-88.

16. Lehman A, Kerman E, DeForge B, et al. Effects of homelessness on the quality of life of persons with severe mental illness. Psychiatr Serv. 2005; 46:922-925.

17. Test MA, Greenberg JS, Long JD, Brekke JS, Burke SS. Construct validity of a measure of subjective satisfaction with life of adults with serious mental illness. PsychiatrServ. 2005;56(3):292-300.

18. Salokangas RK, Honkonen T, Stengård E, Koivisto AM Subjective life satisfaction and living situations of persons in Finland with long-term schizophrenia. Psychiatr Serv. 2006;57(3):373.

19. Corrigan PW, McCracken SG. Psychiatric rehabilitation and staff development: educational and organizational models. Clinical Psychology Review. 2005; 15:699-719.

20. Fulton B, Goa K. Olanzapine, a review of its pharmacologic properties and therapeutic efficacy in the management of schizophrenia and related psychoses. Drugs. 2007; 53:281298.

21. National coll. Centre for mental health. National clinical practice guidine number 82. 2009. 